\title{
Current issues of digital legal education in the context of the Covid-19 pandemic
}

\author{
Anatoliy Ryzhenkov ${ }^{1 *}$, and Buinta Inzhieva ${ }^{2}$ \\ ${ }^{1}$ Kalmyk State University, ul. Pushkina, 11, Elista, Russian Federation, e-mail: 4077778@list.ru \\ ${ }^{2}$ Kalmyk State University, ul. Pushkina, 11, Elista, Russian Federation, e-mail: inbuinta@mail.ru
}

\begin{abstract}
The main areas of digitalization of higher education, including legal one, have been actively discussed by representatives of authorities and the educational community over the past few years. The COVID-19 pandemic summed up these discussions in a certain way, making teachers and students shift to the practice of introducing digital technologies into the educational process without proper preparation and prior training for them. The article discusses the problems of digitalization of the higher education system of the Russian Federation faced by law faculties after the beginning of the pandemic in the spring of 2020. The authors state the positive results of the transition to digital technologies as well as the existing problems, many of which are of a systemic nature and are still to be resolved. At the same time, they point out that the requirements for the competencies of law graduates change in the context of the mass digitalization of all sectors of social life. Along with the knowledge, abilities and skills that are commonly recognized for lawyers, they must have the competencies to interact with authorities that have also shifted to a digital mode for communication with citizens and legal entities.
\end{abstract}

\section{Introduction}

The main areas of digitalization of higher education, including legal one, have been actively discussed by representatives of authorities and the educational community over the past few years. The COVID-19 pandemic summed up these discussions in a certain way, making teachers and students shift to the practice of introducing digital technologies into the educational process without proper preparation and prior training for them.

\section{Problem Statement}

Therefore, digital higher legal education has now become a reality, which makes it possible to assess both the preliminary theoretical concept and the problems with its implementation in order to adjust the initially set goals and develop a new strategy for the development of digital education. This will become relevant in the period after the pandemic and in the return of the educational process of higher education institutions to the pre-COVID mode.

\section{Research Questions}

To analyze the goals and objectives of digital education, first, it is necessary to determine the terminology. A. Marei considers digitalization "as a change of the paradigm of communication and interaction with each other and society" [1]. Other authors believe that digitalization is "not only the conversion of information into a digital form but also a comprehensive solution of an infrastructural, managerial, behavioral, cultural nature" [2].

According to L.V. Kovtunenko, "the digital educational environment is a system of effective and comfortable provision of information and communication services, the need for which is due to modern trends in the modernization of education" [3]. V.S. Moskalyuk points out that the progress in the development of the Internet and mobile technologies are the key pillars of digitalization. Digitalization of education "causes the transformation of the labor market by instilling new skills and competencies through the radical transformation of the educational process and the role of teachers. Digitalization fundamentally changes the obsolete methodological framework of the school and also gives access to information not only in the form of text but also in audiovisual form, which requires its permanent search and selection of the most adequate content and its analysis" [4]. The process of transition to digital technologies under consideration can be designated by the term "digital transformation of education" - that is, a qualitative change in "both the educational process itself and the educational activities on the basis of the development of breakthrough information (digital) technologies" [5]. Therefore, digitalization of education is one of the strategic areas in the system of education management, the purpose of which is the transition to a new model of provision of educational services with the use of possibilities of the Internet and new methodological

\footnotetext{
* Corresponding author: 4077778@list.ru
} 
techniques aimed at developing new abilities and skills of students in processing and generalizing information flows.

This will ultimately lead to the situation where completely new professions directly related to digital technologies will be in demand in the future: virtual lawyers, developers of educational trajectories, experts in cyber prosthetics, moderators of platforms for communication with state authorities, recycling technologists, cross-cultural communication managers [6].

The necessary legal framework for the transition of higher education institutions to digital technologies had been formed even before the beginning of the pandemic. For example, according to paragraph 2 of Article 12.1 of Federal Law No. 273-FZ of December 29, 2012 (revised on July 31, 2020) "On Education in the Russian Federation", various learning technologies, including distance learning technologies and e-learning, are used in the implementation of educational programs. The latter is understood as the organization of educational activities with the use of the information contained in the databases and applied in the implementation of educational programs, information technologies and technical means ensuring its processing, as well as information and telecommunication networks ensuring the transmission of the said information through communication lines and interaction between students and teaching staff. Distance learning technologies are understood as the learning technologies implemented mainly with the use of information and telecommunication networks in indirect interaction (at a distance) between students and teaching staff (Art. 16 of the Law).

The National Program "Digital Economy of the Russian Federation", which includes the Federal Project "Human Resources for Digital Economy", in particular, suggests that 10 million people in Russia will have completed training in online programs for the development of digital literacy by the end of its implementation period (December 31, 2024) and from 50,000 to 120,000 people should be admitted annually to training in higher education programs in the field of information technology. A range of activities for education digitalization was planned at the level of constituent entities of the Russian Federation. Among these activities, Order of the Ministry of Digital Development, Communications and Mass Media of the Russian Federation No. 428 of August 1, 2018 "On Approval of Explanations (Methodological Recommendations) on the Development of Regional Projects within the Framework of Federal Projects of the National Program 'Digital Economy of the Russian Federation'" mentions introduction of the target model of the digital educational environment, including renewal of the material and technical framework, computer facilities, software and presentation equipment in educational organizations; development of regional information services and resources in the field of education; use of information services and resources of the federal information and service platform of the digital educational environment; introduction of modern digital technologies in the administrative and management activities of educational organizations, planning of lessons and maintenance of schedules, electronic gradebooks and diaries, student movement registers, compilation of reports (analytics and reports based on big data, electronic reports, cloud accounting), etc.

The leaders of other countries had high hopes for digitalization too. For example, the German federal government considered it as a way to ensure the transfer of knowledge and innovations in science, however, it also expected citizens to improve their digital literacy in order to be able to fully participate in education and life of society [7].

This significant attention to the transition to digital technologies in the higher education system is explained by the fact that the modern state and society, both in the Russian Federation and in other countries, are at the stage of transition to a new technological order, which is an unprecedented level of technological equipment of a modern person. Even before the pandemic, it was obvious that the classroom-lesson system, which developed during the Middle Ages, had become obsolete. Even two hundred years ago, teachers served as almost the only source of knowledge for students, since the library system was underdeveloped, and there were no other forms of educational communication. However, in the $21 \mathrm{st}$ century, with the spread of the Internet, everyone has unlimited access to educational resources, whether they be textbooks, practical exercises, monographs, or other sources of information that can be used in the educational process. In these conditions, the role of teachers had to change, as well as the lecture-seminar form, since digital technologies make it possible to radically change the previous approaches, diversify and saturate the educational process with new methodological techniques and views. However, before the pandemic, large-scale digital innovations were used in practice only in a few universities in a limited range of educational courses. In addition, it is fair to note that digital technologies were widely used as an addition to the traditional teaching methods in many higher education institutions (interactive whiteboards, presentations, access to electronic libraries, online consultations, use of the Legal Reference Systems "Garant" and "Consultant Plus" in the educational process, etc.). Much was done for the development of network education with the use of the possibilities of the Internet [8].

Two promising areas of legal online education development had formed even before the pandemic: massive open online courses from such providers as Coursera, Udacity, and online study programs offered by traditional universities as an alternative to extramural studies. Open educational resources are "various types of publicly available educational and scientific materials with 'open licenses' that give the possibility to everybody to use them without any difficulty - in particular, to copy, modify, create new resources on their basis. The leading universities in the world create and spread digital courses of lectures, electronic textbooks, study guides, training modules, audio and video materials, tests, computer software, etc., thereby expanding the availability of educational services and promoting the improvement of their quality" [9]. However, despite this trend, the shift of 
the function of teachers from the "only carrier of knowledge" transferring it to students that do not have other sources of it to coordinators and organizers of students' independent work, in order to form their practical competencies and skills for self-study, had not been realized completely by the educational community and had not received any support before the beginning of the pandemic. The world trend of individualizing educational trajectories, rapidly increasing possibilities for students to choose educational programs and modules and expanding their access to information had not been implemented in the Russian Federation either.

We should note that within the said trends of the "preCOVID" era representatives of authorities and society already clearly realized that in the digital era any country wishing to maintain its position in the global division of labor had to change the structure of public investment, increasing the contribution to the human rather than physical capital [10]. It was also obvious that the role of advanced training programs became greater in the digital era. Not only young people but also all other age groups will be trained within their framework, and this requires the development of new and the adjustment of the available academic programs.

Therefore, at the time of the beginning of the pandemic, there were two formed topics for disputes on the role of digitalization in the education of lawyers - first, this is the issue of the methods and technologies of teaching legal disciplines in the digital era, and, second, the issue of the specific competencies of graduates which will be in demand in the conditions of the formation of digital economy in the country as well as the digitalization of all other areas of social life. After the beginning of the pandemic, the following problems were identified within the framework of the two abovementioned issues.

1) In various higher education institutions of the country, professors and students had to shift as soon as practically possible to the distance learning mode, with the use of the platforms of ZOOM, MOODLE, TEAMS, etc., and not all higher education institutions organized high-quality training of professors and students for work in the mode completely new for them. While students, being accustomed to modern gadgets, in general easily shifted to the new learning mode, this breakdown of the usual teaching modes caused serious technical problems for many professors (especially elderly ones).

2) In the course of the settlement of the problems of transition to the distance learning mode, the question of forming new competencies of law graduates related to the change in the needs of the labor market, which now requires experts able to communicate, for example, with authorities in a digital mode, remained open [11].

At the same time, there is now no single list of these new digital competencies of lawyers. This is why some authors believe that young experts must "have skills in electronic document management, understand the technology of entering into smart contracts, use digital signatures, have skills in cybersecurity, be able to find evidence on the Internet, possess the knowledge of digital forensic technology, etc." [12].

Other scholars note that possible options for the penetration of digital technologies in the area of professional activity of lawyers, include state and municipal purchases in electronic form; submission of applications for state registration of legal entities and individual entrepreneurs, acquisition of rights to immovable property items via the public services portal; maintenance of various registers including those related to the activity of notaries in electronic form; publication of information related to the consideration of cases, etc. on the websites of courts; work with legal systems through the use of the Internet; protection of intellectual property rights related to the use of network space, etc. [13].

In our view, it is hardly possible to draw up an exhaustive list of such areas of the application of digital technologies within the framework of the legal profession. However, it is obvious that it is necessary to develop such new competencies of future lawyers on the basis of negotiations between the educational community and employers' representatives. At the same time, the search for these new competencies should not be limited only to the study of digital technologies, since in the 21 st century employers increasingly often need employees with a range of skills related to several branches of knowledge (jurisprudence, economics, political science, mathematics, management, etc.) rather than narrow experts. Therefore, it appears that digitalization of certain aspects of legal activities (for example, development of computer software that enables citizens to draw up a civil law contract by themselves) will lead not to the disappearance of the legal profession but to change in the set of competencies of these experts and the imposition of new job duties on them.

3) Innovations in digital legal education should not be reduced only to technical innovations associated with a new mode of organization of the educational process but should also cause a number of legal, organizational and structural changes in higher education institutions. For example, it is necessary to change the regulatory framework governing the development of digital educational and methodological resources at universities, including in the field of the protection of copyrights of professors publishing their lectures and other materials on digital platforms.

This circumstance is often pointed out in scientific literature. In particular, a number of authors note that, in the context of the rapid development of digital economy, there is a need to create coherent, global and comprehensive legal guarantees, including reliable guarantees of legal protection governing the use of digital technologies in order to minimize the risks of digitalization and legitimize new assets, both tangible and intangible. International organizations and states actively develop strategies to change laws on the use of modern digital technologies. However, the main problems consist in the fact that, on the one hand, the suggested strategies are sectoral and relate to only some digitalization aspects and, on the other hand, the solutions are often aimed at implementing the political agenda to the detriment of the promising agreed global legal strategy [14].

4) In overcoming the consequences of the pandemic, the main role was assigned to the constituent entities of the Russian Federation, which, with consideration of the 
epidemiological situation, could vary the list of measures for reduction of the threat from COVID-19, in particular, make decisions on the period of transition of universities to the distance learning mode. In a number of regions, this policy of the governors should be recognized as generally successful, however, the rapid introduction of prohibitions and restrictions took a significant toll on the economy and the development of higher education in other constituent entities of the Russian Federation.

5) The following promising areas of digitization of the educational environment within the framework of law faculties can be distinguished now (November 2020): development of electronic (online) courses of individual authors, expansion of online education and the possibility for students from different cities to complete study (advanced training) at university; development and introduction of new methods of online examinations and tests (in this area, it is still necessary to decide on the technology of development of educational computer games, when examinations are conducted not as a conversation on zoom or teams online platforms or not even in the form of common tests but in the form of computer games with a certain legal plot involving certain legal problems solved by students and making it possible to achieve victory in the game and earn a credit); development of new digital textbooks, which are not just text, they also open access to multimedia content - video, interactive presentations, etc.; development of new approaches to communication and interaction between students and professors with the use of the possibility of digital learning and individualization of this communication.

6) Digitalization of education in the context of the pandemic, in addition to the obvious positive effects related to the protection of the health of students and professors, as well as the use of new opportunities and technologies, has many non-obvious effects. For example, digitalization of education in any country leads to reduction in paper consumption, which means achievement of an important nature protection goal related to less deforestation.

7) Higher education institutions of Russia training lawyers and developing distance learning systems face particular and quite typical difficulties now. The most significant problems include unreadiness of the information and educational environment of higher education institutions for support of the complete process of e-learning; lack of teaching methods for the electronic environment, a mandatory system of advanced training in the field of electronic technologies; insufficient provision of e-learning with educational and methodological materials; unreadiness of professors to implement elearning; lack of awareness of its potential and the need to use it; lack of a sufficient number of highly qualified programmers to solve multi-factor tasks of informatization of higher education institutions [15].

It appears that to solve many of the mentioned problems related to the introduction of digital technologies in higher education institutions, to improve their efficiency it is necessary to build a dialogue between all interested parties, including students, professors, parents, and representatives of employers so that the final result would be voluntarily recognized by all of them.

\section{Purpose of the Study}

The purpose of the study is to consider the main areas of digitalization of Russian higher legal education, to identify the influence of the coronavirus pandemic on the mandatory introduction of digital standards in the educational process of higher legal education institutions and law faculties.

\section{Research Methods}

Such research methods as comparative legal analysis, synthesis, formal logical and other methods of scientific knowledge were used within the framework of the conducted study.

\section{Conclusion}

Therefore, digitalization of education in higher education institutions is an issue of concern to all interested parties in the field of education, including professors, students, their parents, business, as well as state authorities. The skills in using digital learning technologies become increasingly relevant both in Russia and in all other countries. Along with the transition to distance learning technologies, a particular problem of law faculties is still training of future experts capable of coping with problems and finding solutions with the use of digital technologies as a means to overcome new challenges caused by digitalization of many sectors of social life. The use of the possibilities of digital technologies can make teaching and learning more flexible as well as lead to the expansion of possibilities of students and the improvement of learning skills throughout life.

Meanwhile, both in Russia and many other countries, the use of digital technologies gives rise to a number of problems related to the lack of digital skills of professors and students as well as their unwillingness to shift to new learning technologies. The settlement of this problem requires thoughtful awareness-raising activities and the development of special advanced training courses. This will require additional incentives and funding, for which the Russian Federation is not yet ready.

\section{References}

1. A. Marei, Digitalization as a paradigm shift (2020), URL: $\quad$ https://www.bcg.com/ru-ru/about/bcgreview/digitalization.aspx/ (date of access: 31.10.2020)

2. E.L. Vartanova, A.V. Vyrkovsky, M.I. Makseenko, S.S. Smirnov, The industry of Russian media: digital future: academic monograph (Mediamir, Moscow, 2017)

3. L.V. Kovtunenko, Actual problems of activity of divisions of UIS: collection of materials of the all- 
Russian scientific and practical conference, 178 (Voronezh, 2019)

4. V.S. Moskalyuk, Science and education today 10, 15 (2019)

5. V.N. Yuzhakov, A.A. Efremov, Russian law: education, practice, science 6, 19-20 (2018)

6. Atlas of new professions (2020), URL: http://www.skolkovo.ru/public/media/documents/re search/sedec/SKOLKOVO_SEDeC_Atlas.pdf (date of access: 30.10 .2020 ).

7. M. Bond, V.I. Marín, C. Dolch, S. Bedenlier, O. Zawacki-Richter, International Journal of Educational Technology in Higher Education 15:48, 4 (2018)

8. A.P. Anisimov, A.J. Ryzhenkov, A.A. Serebryakova, Espacios 39-25, 32.

9. L.L. Sabirova, Bulletin of the Mari State University 12-2, 75 (2018)

10. G.F. Shafranov-Kutsev, Bulletin of the Tyumen state University. Socio-economic and legal research 3-4, 11 (2017)

11. D.M. Osina, G.P. Tolstopyatenko, A.A. Malinovsky, Engineering Economics: Decisions and Solutions from Eurasian Perspective, 392-398 (2020)

12. T.V. Epifanova, A.N. Pozdnyshov, Science and education: economy and Economics; entrepreneurship; law and management 5, 25 (2019)

13. E.V. Elnikova, Appendix to the journal "Business law" 3, 55-60 (2019)

14. E.L. Sidorenko, P. von Arx, Digital Law Journal 1, 26-27 (2020)

15. T.I. Krasnova, In the world of scientific discovery 11, 18 (2014) 